\title{
Análise das demandas judiciais de medicamentos: uma abordagem da realidade do Distrito Federal, Brasil
}

\author{
Analysis of drug lawsuits: an approach to the reality of the Federal District, Brazil \\ El análisis de los litigios sobre medicamentos: una aproximación a la realidad del Distrito \\ Federal, Brasil
}

Cosme Santana Cardoso ${ }^{1}$

\begin{abstract}
RESUMO: Introdução: As publicações das Políticas Nacionais de Medicamentos e de Assistência Farmacêutica trouxeram muitos avanços e conquistas na área de medicamentos. Apesar dos avanços no acesso aos medicamentos no SUS, tem-se observado uma demanda judicial crescente pelo seu fornecimento. Objetivo: O objetivo deste trabalho foi identificar, quantificar e qualificar os medicamentos que foram garantidos mediante ações judiciais no TJDFT em 2011, além de verificar se houve a diminuição da quantidade de medicamentos padronizados garantidos em juízo, registrados no sistema de informações judiciais da Procuradoria Geral do Distrito Federal. Metodologia: A pesquisa realizada é classificada como documental, descritiva, com coleta retrospectiva de dados, expressada de forma quali-quantitativa. Resultados: Dos 250 processos tabulados, 216 foram utilizados para este trabalho. $100 \%$ dos processos analisados referiam-se a ações individuais. Dos processos analisados, destaca-se que 246 medicamentos foram judicializados no DF em 2011. A grande maioria dos medicamentos solicitados não constava em nenhuma lista oficial. Conclusão: Portanto, fica evidente uma atuação do Judiciário local não condizente com as políticas públicas do SUS.
\end{abstract}

Palavras-chave: Direito a Saúde. Medicamentos. Ações Judiciais. Listas Oficiais.

ABSTRACT: Introduction: The National Medicines Policy and the Pharmaceutical Assistance publications brought many advances and achievements in the field of medicines. Therefore advances in access to medicines in to SUS, there has been a lawsuit by increasing its supply. Objective: The objective of this study was to identify and quantify the drugs that were secured through litigation in TJDFT in 2011, and see if there was a decrease of the amount of standard drugs secured in court, registered in the system of judicial information from the Procuradoria Geral do Distrito Federal. Results: The research is classified as documentary, descriptive and retrospective data collection, expressed in a quali-quantitative way. Between 250 cases tabulated, 216 were used for this research. $100 \%$ of the cases analyzed refer to individual litigations, where $82.5 \%$ of the total were injunctions and coercive actions. Conclusion: Of the cases examined, it is noteworthy that 246 medicines were judicialized in DF in 2011. While the large majority of medicines requested was not included in any official list. Therefore, there is clearly a work of the local judiciary is not consistent with the public policy of the SUS.

Keywords: Right to Health. Drugs. Lawsuits. Official Lists.

\footnotetext{
${ }^{1}$ Graduado em Farmácia e Bioquímica pela Universidade Federal da Bahia (UFBA); Servidor Público Federal e Distrital; Especialista em Citologia Clínica-Conselho Federal de Farmácia. Email: cosmesantana@uol.com.br
} 
RESUMEN: Introducción: Las publicaciones de Políticas Nacionales de Drogas y Servicios Farmacéuticos trajeron muchos avances y logros en el ámbito de la droga. A pesar de los avances en el acceso a los medicamentos en el SUS, se ha visto una creciente demanda de suministro judicial. Objetivo: El objetivo de este estudio fue identificar, cuantificar y cualificar los medicamentos que han sido garantizados por demandas en TJDFT en 2011, y si se ha producido una disminución en la cantidad de los medicamentos estándares garantizados en la corte, grabado en el sistema de información judicial de la Procuraduría General del Distrito Federal. Metodologia: La investigación se clasifica como un documental, descriptiva, con recogida de datos retrospectiva, expresada en forma cualitativa y cuantitativa. Resultados: De los 250 casos, cuadros 216 se utilizaron para este trabajo. 100\% de los casos analizados se refirió a las acciones individuales. Los procesos involucrados, se insiste en que las drogas fueron 246 judicializado en la Ciudad de México en 2011. Conclusión: La gran mayoría de los medicamentos solicitados no aparecerá en ninguna lista oficial. Por lo tanto, el rendimiento de un poder judicial local no es coherente con la política pública del SUS es evidente.

Palavras-Ilave: Derecho a la salud. Medicamentos. Proceso Judicial.

\section{Introdução}

A saúde é considerada pela Organização Mundial da Saúde (OMS) como o primeiro princípio básico para a felicidade, as relações harmoniosas e a segurança de todas as pessoas (1). A Declaração Universal dos Direitos Humanos de 1948, em seu artigo XXV, item 1, declara que todo ser humano tem direito a um padrão de vida capaz de assegurarIhe e a sua família saúde e bem-estar, inclusive cuidados médicos e os serviços sociais indispensáveis (2). A Constituição da República de 1988 , em seu artigo $6^{\circ}$, positiva em nosso ordenamento jurídico uma nova concepção de direitos pertencentes à coletividade e ligados à justiça distributiva e ao bem-estar social, os direitos sociais. Estes direitos têm o objetivo de promover a justiça social e uma distribuição mais equânime, integral e universal dos recursos econômicos e sociais. Esses direitos continuam a ser garantidos nos artigos $196 \mathrm{a}$ 200, os quais tratam sobre a saúde como direito da cidadania (de todos), a equidade e a integralidade na prestação das ações e serviços de saúde, dentre outros. Além da Constituição Federal, o direito à saúde e, consequentemente, o direito à assistência farmacêutica estão positivados em outras normas infralegais.

A Assistência Farmacêutica (AF) é parte integrante das ações de assistência terapêutica integral à saúde e envolve a alocação de volumosos recursos públicos ao setor. O direito à saúde foi regulamentado pela Lei Orgânica da Saúde (Lei 8080/90), que em seu artigo 6o determina, como uma das funções do SUS, a formulação da política de 
medicamentos e a responsabilidade pela execução de ações de assistência terapêutica integral, inclusive farmacêutica (3).

A AF foi estabelecida como a Política Nacional de Assistência Farmacêutica (PNAF) pela Resolução CNS no 338, de 6 de maio de 2004 (BRASIL, 2004). Após as publicações das Políticas Nacionais de Medicamentos e de Assistência Farmacêutica houve muitos avanços e conquistas tanto no acesso a medicamentos constantes nas listas oficiais como nos Protocolos Clínicos e Diretrizes Terapêuticas (PCDT). Apesar dos avanços no acesso aos medicamentos no SUS, tem-se observado uma demanda judicial crescente pelo seu fornecimento (4).

O direito à assistência integral farmacêutica implica a responsabilidade compartilhada entre os entes federativos na garantia da equidade no acesso aos medicamentos no SUS, de forma a garantir o acesso igualitário e universal aos medicamentos para a assistência integral à saúde dos cidadãos (4).

Na opinião de Delduque \& Marques,

Os cidadãos munidos de prescrições médicas oriundas tanto de serviços públicos quanto privados de saúde, e com base no direito à saúde garantido pelo ordenamento jurídico, vem demandando juridicamente o Estado para que este, representado por seus entes federados, forneça-Ihes determinado medicamento (5).

Porém, a garantia do direito à saúde no Brasil é muito complexa, pois requer, dentre outros, gastos elevados e depende de uma política pública. Mas, como fazer para garantir um direito universal e integral para todos, já que a própria OMS considera a saúde como um item essencial para a felicidade?

Diante do exposto, é que surge a problemática em questão: Quais os medicamentos e as respectivas qualidades e quantidades que foram garantidos por meio de decisões judiciais no Distrito Federal no ano de 2011?

Delduque \& Marques (5) demonstraram que as ações judiciais que tratavam de medicamentos apontavam para um grande número de provimentos no sentido de garantir produtos que estão nas listas oficiais. Destacaram, ainda, que a totalidade dos processos analisados referia-se a ações individuais e, em sua maioria, tramitavam como ações 
cominatórias ${ }^{2}$. Nesse sentido, é importante investigar a realidade atual do DF, pois com a criação do Comitê Executivo da Saúde em 2011 estima-se que esses medicamentos tenham sido, em sua maior parte, não padronizados e os padronizados resolvidos pela via extrajudicial.

Este artigo apresenta os resultados de pesquisa sobre as demandas judiciais de medicamentos no Tribunal de Justiça do Distrito Federal e Territórios (TJDFT), no ano de 2011, bem como busca evidenciar quais medicamentos que foram mais garantidos por meio das ações judiciais e sua inserção ou não nas listas oficiais ou PCDT.

\section{A judicialização do direito à saúde}

\section{Histórico e conceitos}

Como destacam Vianna et al (7), o termo judicialização pode ser utilizado para descrever o alargamento das relações sociais como objetos do direito, passíveis de serem trazidas à discussão jurídica e, também, judicial. Apontam os autores que as transformações trazidas pela Constituição Federal de 1988 no Brasil alargam as possibilidades de ações junto ao Poder Judiciário, e assim este Poder vem decidindo crescentemente sobre os mais diversos temas sociais, políticos e também econômicos, que passam a ser abrigados pelo direito. Dentre estes temas, encontra-se a saúde.

A origem da judicialização da saúde ainda é duvidosa no Brasil, além da amplitude e diversificação das demandas nos tribunais. Essa dúvida decorre da "ausência de estudos sistemáticos e comparativos" e da dimensão da "judicialização e seus diferentes níveis de expressão nas cortes" (7).

A judicialização da saúde iniciou-se com a busca pelos medicamentos antirretrovirais, para a defesa do vírus da imunodeficiência adquirida - HIV. Observou-se ainda que as prescrições continham tanto medicamentos incorporados como não incorporados pela Assistência Farmacêutica (AF) do SUS, além do aumento exponencial das ações judiciais e dos gastos com medicamentos (8).

\footnotetext{
${ }^{2}$ Ações cominatórias são aquelas ações propostas para se obter, judicialmente, o bem da vida pleiteado no caso concreto, podendo ser solicitado ao juiz que fixe multa, a qual poderá ser diária, para ser paga pelo réu enquanto não cumprir a obrigação de fazer.
} 
Por conta desses fatos, houve uma preocupação do Poder Judiciário, representado pelo Supremo Tribunal Federal (STF), o qual designou a Audiência Pública ํㅜ 04 com o intuito de reunir representantes técnicos e jurídicos vinculados à saúde pública para discussão do tema. Dessa audiência, o Conselho Nacional de Justiça (CNJ) editou a Recomendação no 31/2010, com informações para garantir mais eficiência na solução das demandas judiciais relativas à saúde (9).

O CNJ editou, então, a Resolução ํำ107/2010, instituindo no seu âmbito o Fórum Nacional para o monitoramento e resolução das demandas de assistência à saúde, denominado Fórum Nacional Judiciário da Saúde, constituído pelos Comitês Executivos Estaduais com a finalidade de coordenação e execução de ações específicas consideradas relevantes.

Atendendo à determinação da Resolução 107/2010, do CNJ, foi criado em 2011 o Comitê Executivo Distrital da Saúde. Dentre as funções deste Comitê estão a monitoração das ações judiciais que envolvam a garantia do acesso à saúde, como o fornecimento de medicamentos, no âmbito do DF (9).

Nesse sentido, espera-se que o fenômeno da judicialização seja minimizado com a criação desses Comitês Executivos da Saúde, assegurando, com isso, a dignidade humana e o direito social à saúde constitucionalmente garantidos.

\section{O direito à saúde na Constituição Federal e nas normas infraconstitucionais}

As Constituições brasileiras anteriores a de 1988 tratavam a saúde vinculada ao mundo do trabalho, reduzindo-a ao conceito de assistência sanitária, hospitalar e médicopreventiva.

A Constituição atual estabeleceu uma quebra de paradigma, ao estabelecer, no artigo $1^{\circ}$, inciso III, a dignidade da pessoa humana como fundamento da República Federativa do Brasil, e a promoção do bem de todos, no artigo $3^{\circ}$, inciso IV, como um de seus objetivos (10). Esses foram os grandes impulsionadores do direito à saúde no Brasil.

A saúde está inserida no rol dos direitos sociais constantes no artigo $6^{\circ} \mathrm{e}$ tratada como direito de todos e dever do Estado, no artigo 196 da Carta Magna. Já o artigo 197 declara que as ações e serviços de saúde são de relevância pública, que nada mais é do que a realização dos objetivos e fundamentos da República Federativa do Brasil - artigos $1^{\circ}$ e $2^{\circ}$ 
(10). Dessa maneira, um serviço público relevante em confronto com outro que não tenha essa qualificação, o administrador público deverá privilegiar a saúde, como por exemplo, na garantia de um determinado medicamento essencial a uma vida digna e saudável.

O artigo 198 da Constituição Pátria afirma que as ações e serviços públicos de saúde integram uma rede regionalizada e hierarquizada, organizada segundo as diretrizes da descentralização, da integralidade da assistência e da participação da comunidade. As atribuições dessa rede, denominada Sistema Único de Saúde (SUS), estão enumeradas no artigo 200 (10).

Para consolidar esse direito e para organizar todo o Sistema de Saúde foi promulgada a Lei Orgânica da Saúde. As autoras, Delduque \& Marques (5), citam que para materializar e organizar o SUS no Brasil foram promulgadas as Leis 8080/1990 e 8142/1990. A Lei 8080/1990, em seu artigo $6^{\circ}$, inciso I, alínea d, estabelece que um dos campos de atuação do SUS é a execução de ações de "assistência terapêutica integral, inclusive farmacêutica". Em seu artigo $7^{\circ}$ estabelece que a assistência à saúde deve ser prestada de forma integral, universal e igual (3).

Com o objetivo de enfrentar os gargalos e produzir inovações na organização e nos processos de gestão do sistema, foi implementado o Pacto pela Saúde 2006, aprovado pela Portaria GM/MS n³99/2006, nas suas três dimensões: Pacto pela Vida, em Defesa do SUS e de Gestão. Dentro do Pacto de Gestão existe o Bloco de Financiamento da Assistência Farmacêutica, segundo o qual a Assistência Farmacêutica será financiada pelos três gestores do SUS (11).

A Lei 12401/2011, que alterou a Lei 8080/1990, declara em seu Título II, no Capítulo VIII, o qual trata sobre a assistência terapêutica e a incorporação de tecnologia em saúde no âmbito do SUS, que a assistência terapêutica integral a que se refere a alínea d, inciso I, art. $6^{\circ}$ da Lei 8080/1990, consiste em dispensar as prescrições dos medicamentos e dos produtos de interesse à saúde que estejam em conformidade com os PCDT e, na ausência destes, com base nas relações de medicamentos instituídas pelos gestores federal, estaduais, distrital e municipais (12). Essa Lei aumentará o acesso da população a medicamentos e procedimentos relacionados à saúde; inclusive os casos demandados por decisão judicial. Com isso, o Judiciário contará com parâmetros mais precisos para subsidiar as suas ações na área de saúde. 
O Decreto 7508/2011, que regulamentou a Lei 8080/90, visa dar mais transparência a essa estrutura, com a finalidade de garantir maior segurança jurídica na fixação das responsabilidades dos entes federativos. A regulamentação contribuirá, também, para um melhor esclarecimento do Ministério Público e do Poder Judiciário a respeito das responsabilidades - competências e atribuições - dos entes federados nas redes de atenção à saúde. Além disso, preconiza em seu artigo 28 que o acesso à assistência farmacêutica deve ser universal e igualitário (13).

Nesse diapasão, após mais de uma década de luta, é finalmente sancionada a lei que regulamenta os gastos com saúde. A Emenda Constitucional 29/2000 (EC 29/2000), que obriga os governos federal, estadual e municipal a aplicarem percentuais mínimos na área da saúde, foi regulamentada por meio da Lei Complementar 141/2012. Essa Lei regulamenta o $\S 3^{\circ}$ do art. 198 da CF para dispor sobre os valores mínimos a serem aplicados anualmente pelos entes federados em ações e serviços públicos de saúde (14).

Dentro desse conjunto de normas temos ainda a Política Nacional de Medicamentos (PNM), aprovada pela Comissão Intergestores Tripartite e pelo Conselho Nacional de Saúde, constante na Portaria GM/MS 3916/1998, como parte fundamental da Política Nacional de Saúde, com o propósito de "garantir a necessária segurança, eficácia e qualidade destes produtos, a promoção do uso racional e o acesso da população àqueles considerados essenciais". Entre as suas principais diretrizes estão o estabelecimento da relação de medicamentos essenciais e a reorientação da assistência farmacêutica (15).

A Relação Nacional de Medicamentos Essenciais (Rename), aprovada pela Portaria GM/MS 507/1999, é uma publicação do Ministério da Saúde, a qual consta os medicamentos para o controle das principais doenças que acometem o povo brasileiro. Essa Relação tem o papel de racionalizar a saúde pública no Brasil e serve de base para os estados e municípios elaborarem suas listas de assistência farmacêutica básica (11).

Os PCDT são oficializados por meio da edição de Portarias pelo Ministério da Saúde, após serem submetidos à consulta pública antes de serem publicados oficialmente (16). São desenvolvidos com base em evidência científica; estabelecem critérios de diagnóstico, tratamento e monitoramento clínico de agravos à saúde com a finalidade de nortear uma assistência médica e farmacêutica efetiva e de qualidade. Isso permite que os PCDT sejam 
um instrumento na gestão pública para a aquisição e dispensação de medicamentos em todos os níveis de assistência farmacêutica (17).

Para Marques (16), a PNM e os PCDT, resumem as decisões coletivas que o Estado deve tomar em relação à assistência farmacêutica visando a garantia do direito social à assistência farmacêutica.

A Lei Orgânica do Distrito Federal, de 1993, em seu artigo $3^{\circ}$, trata a saúde como um dos seus objetivos prioritários. O artigo 207, inciso XXIV, declara que é competência do SUS no DF "prestar assistência farmacêutica e garantir o acesso da população aos medicamentos necessários à recuperação de sua saúde" (18).

Observa-se, com isso, que com a promulgação da Constituição Federal de 1988, surgiram inúmeras iniciativas legais que contribuíram para viabilizar o pleno direito à saúde no Brasil.

\section{O Poder Judiciário e a garantia do acesso a medicamentos no Distrito Federal}

Há um crescente aumento dos gastos com saúde desde a criação do SUS (19). Os gastos com medicamentos são um bom exemplo disso, no sentido de que o Estado é pressionado a garantir à população, além dos medicamentos constantes das listas oficiais, aqueles de uso continuado e de alto custo (20). Isso resulta na realocação de verbas públicas para garantir um interesse individual em detrimento da coletividade, haja vista o orçamento já ser escasso.

Para Romero (21), "as políticas de medicamentos e de assistência farmacêutica do País passaram por significativas mudanças na segunda metade da década de 1990". Isso pode ser verificado pelo grande número de normas que surgiram no sentido de regulamentar o setor nesse período.

A judicialização da Política de Assistência Farmacêutica tem ganhado "importância teórica e prática, face ao crescimento exponencial das ações que demandam medicamentos para o Estado por meio do Judiciário" (5).

Segundo Santana (20), as ações judiciais para aquisição de medicamentos elevam os gastos dos estados com saúde a cada ano. Essa situação também é convivida pelo DF, cujo movimento tem crescido muito rápido nos últimos anos. 
Essa problemática tem encontrado no DF um local propício para o crescimento do movimento da judicialização das políticas de saúde, cujos litígios saem das salas dos gestores públicos para os gabinetes dos juízes (20). Apesar de encontrarmos um sistema de saúde relativamente bem estruturado, porém mal administrado (21). Isto fica bem evidente nos noticiários locais e nacionais a respeito da qualidade da prestação da saúde pública no DF.

Inicialmente, o DF demonstrava pouca disposição em atender às demandas relativas à saúde, além de tentar extinguir os processos sem apreciar o mérito. Porém, tais estratégias não funcionaram, pois foram sempre rejeitadas pelo TJDFT. Daí o DF passou a tomar as suas decisões embasadas nos méritos das demandas e de acordo com o caso concretamente julgado pela justiça (20).

Santana (20) acrescenta ainda que as demandas judiciais por medicamentos no DF são levadas ao Judiciário pelos cidadãos ou pelo Ministério Público (MP) que buscam garantir o direito à saúde e à vida, e pela Administração Pública em sua defesa própria. O autor relata que para o Judiciário local a padronização de medicamentos e a adoção de protocolos clínicos é "exigência de índole meramente administrativa" (20), prevalecendo o receituário médico.

A judicialização da saúde no DF, que começou com a garantia do acesso dos pacientes aidéticos aos antirretrovirais, aumentou e alcançou um número diversificado de medicamentos.

Dentro desse contexto, foi realizada uma pesquisa descritiva, documental, expressada de forma quali-quantitativa, com levantamento de dados judiciais sobre medicamentos.

A finalidade deste trabalho é identificar, qualificar e quantificar os medicamentos que foram garantidos mediante ações judiciais no Distrito Federal em 2011, além de verificar se houve a diminuição de medicamentos padronizados garantidos em juízo e, bem como, tentar chegar a possíveis conclusões. 


\section{Metodologia}

Tratou-se de uma pesquisa descritiva, documental com coleta retrospectiva de dados judiciais sobre medicamentos na Procuradoria Geral do Distrito Federal, no ano de 2011, expressada de forma quantitativa, mas que se utilizou também de análise qualitativa.

As variáveis consideradas no estudo foram quantidades de medicamentos e medicamentos garantidos, tipos de ações judiciais, listas de medicamentos oficiais e Protocolos Clínicos e Diretrizes Terapêuticas.

Os dados foram obtidos a partir do banco de dados do sistema de informações judiciais da Procuradoria de Meio Ambiente, Saúde e Patrimônio Urbanístico (PROMAl), especializada em atendimento das ações relacionadas à saúde, da Procuradoria Geral do Distrito Federal (PGDF), no mês de setembro de 2012. Destaca-se que o banco de dados consultado não é de acesso público. Esses dados foram fornecidos diretamente pela instituição, após solicitação junto à PROMAI, já em formato de planilha excel, onde se filtrou as ações relacionadas a medicamentos do ano de 2011, após serem sistematizados utilizando a palavra-chave "medicamento" e o campo filtrado "assunto". O número total de ações obtidas após a filtragem foi 250.

Para os processos constantes na planilha que não continham o nome do medicamento no campo assunto foi realizada uma busca no site do Tribunal de Justiça do Distrito Federal e Territórios (TJDFT) utilizando como critério os números dos respectivos processos, com o objetivo de localizar os nomes dos medicamentos.

Foi acessado o portal do TJDFT, no Link "consultas", na $1^{\text {a }}$ e na $2^{\text {a }}$ Instâncias utilizouse como tipo de pesquisa o número do processo. Nos processos vinculados à $1^{\mathrm{a}} \mathrm{e}$ à $2^{\mathrm{a}}$ Instâncias, no item "origem", verificou se constava ou não o nome do medicamento garantido.

Das 250 demandas judiciais analisadas durante o ano de 2011 no DF, 216 foram usadas para o estudo, pois não foi possível identificar o medicamento solicitado nos 34 processos excluídos desta pesquisa.

As informações obtidas foram analisadas estatisticamente e expostas por meio de tabelas excel. 


\section{Resultados e discussão}

Dos 250 processos constantes da planilha, $216(86,4 \%)$ foram selecionados para o estudo. Pois, 34 (13,6\%) dessas demandas não constavam a identificação do medicamento no campo assunto ou eram outros produtos para saúde que não medicamento ou eram solicitação de procedimento médico.

Salienta-se que $100 \%$ dos processos analisados referiam-se a ações individuais, as quais tramitavam, em sua maioria $(60,7 \%)$, como mandados de segurança e $21,8 \%$ como ações cominatórias, resultando em $82,5 \%$ do total (tabela 1 ).

Tabela 1 - Tipos de ação judicial que demandaram medicamentos no DF em 2011

\begin{tabular}{lcc}
\hline \multicolumn{1}{c}{ Ação judicial } & Quantidade & Porcentagem \\
\hline Mandado de segurança & 131 & $60,70 \%$ \\
Ação Cominatória & 47 & $21,80 \%$ \\
Obrigação de fazer & 7 & $3,20 \%$ \\
Agravo de instrumento & 6 & $2,80 \%$ \\
Procedimento ordinário & 5 & $2,30 \%$ \\
Ação ordinária & 4 & $1,80 \%$ \\
Outros & 16 & $7,40 \%$ \\
Total & 216 & $100,00 \%$ \\
\hline
\end{tabular}

Fonte: Sistema de informações judiciais da PGDF sobre processos relacionados a medicamentos julgados no DF em 2011

Em estudo semelhante, no que se referem aos tipos de ações judiciais no DF, Delduque e Marques (5) encontraram resultado idêntico em relação às ações individuais e verificaram, ainda, que a maioria $(97,7 \%)$ dessas ações tramitava como ações cominatórias. O presente trabalho mostra que em relação à natureza da ação, ainda há a predominância das ações cominatórias - sobretudo os mandados de segurança - que perfazem $82,5 \%$ do total de ações. Esses resultados são semelhantes aos encontrados por Romero em 2008 e 2010, em que predominaram as ações cominatórias e os mandados de segurança com $57 \%$ do total e $60 \%$, respectivamente.

Observa-se que as ações que demandam medicamentos no DF ainda continuam a ser solicitações individuais, pois não se evidenciou nenhuma ação coletiva relacionada a medicamentos. Dado semelhante ao encontrado por Delduque \& Marques (5), onde 100\% das ações estudadas foram demandadas de maneira isolada. 
É importante salientar que no DF a demanda por medicamentos é proporcionalmente menos importante do que demonstra a literatura brasileira em que aparece como bem mais judicializado. No período de 2005 a 2010, o fornecimento de medicamentos foi garantido, pelo Judiciário local, em apenas $16 \%$ das ações analisadas (7).

Do total de processos analisados, destaca-se que 246 medicamentos foram judicializados no DF em 2011, em uma média de 1,14 por ação judicial. Enquanto que Delduque \& Marques (5) encontraram uma média de 2,63 medicamentos por ação judicial, média semelhante a encontrada no Rio de Janeiro por Pepe et. al (8), os quais evidenciaram que naquele Estado existe uma média de 3,25 medicamentos solicitados por ação. Isso demonstra que a quantidade de medicamento solicitado por ação individual vem em uma tendência decrescente.

Os medicamentos mais judicializados segundo o seu princípio ativo foram: Fator VIII concentrado - 14 (5,7\%), Fator VIII recombinante - 12 (4,9\%); Palivizumabe - 6 (2,4\%); Sorafenib - 6 (2,4 \%); Aripiprazol, Bortezomibe, Fulvestranto, Temozolomida e Pregabalina cada um com 5 (2,0 \%) (tabela 2).

Esses resultados são contrários aos achados por Delduque \& Marques (2011), com exceção do Aripiprazol, cujos medicamentos mais demandados em juízo foram, na seguinte ordem de aparição: Zyprexa (Olanzapina), AAS - Ácido Acetil Salicílico, Humira (Adalimumabe), Rivotril (Clonazepam), Aripiprazol (Aripiprazol), Azopt (Brinzolamina) e Captopril (Captopril). Inclusive quanto ao uso desses medicamentos, em que, na sua maioria, eram psicotrópicos, diferentemente dos encontrados no presente trabalho em que a maioria dos medicamentos era para uso antineoplásico (Sorafenib, Bortezomibe, Fulvestranto, Temozolomida, Cetuximabe e Rituximabe). 
Tabela 2 - Medicamentos mais judicializados no DF em 2011

\begin{tabular}{lcc}
\hline \multicolumn{1}{c}{ Medicamento } & Frequência & Lista Oficial ou Protocolo Clínico Oficial \\
\hline Fator VIII & 14 & sim \\
Fator VIII & 12 & não \\
recombinante & 6 & não \\
Palivizumabe & 6 & não \\
Sorafenibe & 5 & não \\
Aripiprazol & 5 & não \\
Bortezomibe & 5 & não \\
Fulvestranto & 5 & não \\
Pregabalina & 5 & não \\
Temozolomida & 4 & não \\
Cetuximabe & 4 & sim \\
Globulina antitimócito & 4 & sim \\
Itraconazol & 4 & não \\
Rituximabe & 4 & não \\
Duloxetina & &
\end{tabular}

Fonte: Sistema de informações judiciais da PGDF sobre processos relacionados a medicamentos julgados no DF em 2011

Destaca-se, ainda, que entre os medicamentos mais judicializados, quase todos possuíam registro na Agência Nacional de Vigilância Sanitária/Ministério da Saúde, com exceção do Cetuximabe, antineoplásico, que ainda não possuía registro em 2011.

Dentre os 246 medicamentos identificados nas ações judiciais, apenas 53 $(21,5 \%)$ constavam na RENAME e $69(28,0 \%)$ estavam presentes na REME-DF. Enquanto que a maioria dos medicamentos solicitados não constava em nenhuma lista oficial. Dos medicamentos não presentes nas listas oficiais e PCDT, o Fator VIII recombinante, usado na prevenção e controle da hemorragia em pacientes com deficiência congênita do fator VIII (Hemofilia $A$ ), foi solicitado com maior frequência (12 solicitações). Esses dados demonstram que houve uma melhor padronização dos medicamentos no DF, haja vista que os medicamentos atualmente garantidos nas ações iniciais são não padronizados. 
Tabela 3 - Medicamentos que constam ou não em Listas Oficiais ou Protocolos Clínicos

\begin{tabular}{lcc}
\hline $\begin{array}{l}\text { Lista Oficial ou Protocolo Clínico } \\
\text { Oficial }\end{array}$ & $\begin{array}{l}\text { Quantidade de processos que } \\
\text { continham medicamentos na } \\
\text { lista oficial ou protocolo clínico } \\
\text { oficial }\end{array}$ & $\begin{array}{l}\text { Quantidade de } \\
\text { medicamentos }\end{array}$ \\
\hline RENAME & 50 & 53 \\
REME-DF & 59 & 69 \\
PCDT & 31 & 31 \\
RENAME/REME-DF/PCDT & 05 & 05 \\
Não constam na RENAME & 166 & 193 \\
Não constam na REME-DF & 157 & 177 \\
\hline
\end{tabular}

Fonte: Sistema de informações judiciais da PGDF sobre processos relacionados a medicamentos julgados no DF em 2011

Delduque \& Marques (5) observaram que ao menos um medicamento solicitado na petição inicial estava incluso em alguma lista oficial do SUS ou PCDT, e que as peças processuais constavam medicamentos ausentes e medicamentos constantes dessas listas oficiais e PCDT. No entanto, constataram que apenas $37,5 \%$ dos medicamentos identificados não pertenciam a REME/DF. Esses dados não apresentam semelhança aos encontrados pelo presente trabalho, o qual observou que dos 216 processos analisados, 98 $(45,4 \%)$ destes contemplavam pelo menos um medicamento que constava em uma lista oficial ou no PCDT, e 59 (27,3\%) dos processos analisados continham medicamentos os quais constavam na REME-DF, e não a maioria, conforme tabela 3.

Em relação à inserção do medicamento nos PCDT do Ministério da Saúde, foi constatado que apenas 45 medicamentos solicitados constavam nesses Protocolos (5). No presente trabalho encontramos resultado semelhante, onde 31 medicamentos demandados faziam parte dos PCDT, apesar de mostrar uma tendência também decrescente.

Ressalta-se, ainda, que entre os 216 processos analisados, foram encontrados 118 processos $(54,6 \%)$ em que os medicamentos solicitados não constavam em ao menos uma lista oficial ou PCDT; 98 processos (45,4\%) em que pelo menos um medicamento solicitado constava em alguma lista oficial ou PCDT; 21 processos (9,7\%) contemplavam mais de um medicamento.

Somente $5(2 \%)$ do total de medicamentos constantes nos processos analisados estavam contemplados ao mesmo tempo na RENAME, REME-DF e PCDT (tabela 3). Sendo que esses medicamentos se referiam somente a três princípios ativos diferentes: 
Carbamazepina (1), Valproato de sódio (3) e Metformina (1). 193 não constavam na RENAME e 177 na REME-DF.

Do total de medicamentos analisados, 111 (45,1\%) estavam contemplados em ao menos uma lista oficial (RENAME, REME-DF) ou PCDT. Enquanto que 135 (54,9\%) não estavam contemplados em nenhuma lista oficial ou protocolo clínico. Esses dados apresentam uma tendência de inversão aos achados por Delduque \& Marques (2011), que do total de 229 medicamentos analisados, encontraram que 37,7\% não se enquadram em nenhuma lista oficial ou PCDT, ao passo que $62,3 \%$ se enquadram em uma ou outra lista, ou nas duas.

Além disso, na planilha fornecida pela PGDF, alguns medicamentos não constavam a informação de concentração ou forma de apresentação, o que pode acarretar em viés de análise, pois, a depender dessas informações, alguns medicamentos que não se enquadraram nas listas oficiais nem nos PCDT, poderiam vir a ser contabilizados como sendo contemplados em alguma lista oficial ou PCDT.

\section{Conclusões}

De acordo com os resultados obtidos foi possível observar que houve uma diminuição considerável dos medicamentos padronizados garantidos em juízo. A realidade atual do DF demonstra que com a criação do Comitê Executivo da Saúde em 2011 a garantia desses medicamentos tenha sido, em sua maior parte, resolvida pela via extrajudicial. Isso pode ter refletido no grande número de medicamentos não constantes das listas oficiais nem dos PCDT garantidos nas ações iniciais em 2011 pelo Judiciário local.

Ao se analisarem as variáveis estudadas isoladamente, observou-se que em relação à natureza da ação ainda há a predominância das ações cominatórias, principalmente os mandados de segurança - que constituíram $82,5 \%$ do total das ações garantidas. Dentro dos resultados obtidos, o grupo de processos estudados demonstrou que esses tipos de ações continuam predominando em todos os estudos realizados até o presente momento.

Pôde-se notar que tanto neste trabalho como nos outros analisados a justiça no DF ainda continua deliberando ações individuais relacionadas aos medicamentos. Haja vista a ausência de ação coletiva requerendo este tipo de bem, em detrimento das ações individuais que totalizaram $100 \%$ dos processos analisados. 
Apesar da totalidade das decisões serem baseadas em ações individuais, o presente trabalho demonstra que a quantidade de medicamento solicitado por ação isolada vem em uma tendência decrescente a cada ano, já que a média de medicamentos solicitados por ação foi de 1,14, Delduque \& Marques (2011) encontraram uma média de 2,63 e no Rio de Janeiro, Pepe et al (2010b), evidenciaram uma média de 3,25.

$\mathrm{Na}$ variável medicamentos mais garantidos, o Fator VIII concentrado, usado principalmente para terapia de reposição no tratamento da Hemofilia A e no controle clínico da doença de von Willebrand, foi o que apresentou maior frequência (5,7\%). Dentre os não padronizados, o Fator VIII recombinante apareceu em 12 solicitações (4,9\%). Demonstrando que pode ter havido falha na quantidade adquirida ou na programação das compras daquele medicamento, já que ele é padronizado. Além disso, como a maioria dos medicamentos mais judicializados não constavam nas listas oficiais, isso refletirá na política pública elaborada para o setor, pois como sabemos, os recursos são escassos para suprir demandas individuais não constantes em tais políticas, prejudicando, com isso, a prestação do serviço à coletividade.

Em relação aos medicamentos que constam ou não em Listas Oficiais ou Protocolos Clínicos, apenas 53 (21,5\%) constavam na RENAME, 69 (28,0\%) estavam presentes na REME-DF e 31 (12,6\%) nos PCDT. Esses dados demonstram que houve uma melhor padronização dos medicamentos no DF, apesar do mais garantido pelo Poder Judiciário em 2011 ser um medicamento padronizado (o fator VIII concentrado). Haja vista que a grande maioria dos medicamentos atualmente garantidos nas ações iniciais são não padronizados.

Observou-se também que dos 216 processos analisados, 98 (45,4\%) destes contemplavam pelo menos um medicamento que constava em uma lista oficial ou no PCDT, e $59(27,3 \%)$ dos processos analisados continham medicamentos os quais constavam na REME-DF. Foram encontrados ainda 118 processos $(54,6 \%)$ onde os medicamentos solicitados não constavam em ao menos uma lista oficial ou PCDT e, apenas, 21 processos $(9,7 \%)$ contemplavam mais de um medicamento.

Destaca-se ainda que apenas 3 princípios ativos faziam parte dos 5 medicamentos analisados nas petições iniciais contemplados ao mesmo tempo na RENAME, REME-DF e PCDT: Carbamazepina (1), Valproato de sódio (3) e Metformina (1). E 193 não constavam na RENAME e 177 na REME-DF. Isso corrobora com a constatação anterior de que houve 
uma melhoria no processo de padronização dos medicamentos no DF, devido ao grande número de medicamentos não padronizados atualmente garantidos nas ações iniciais.

O presente estudo demonstrou que a maioria dos medicamentos garantidos foram não padronizados, ou seja, não constavam nas listas oficiais do Ministério da Saúde nem do DF nem nos PCDT, deduzindo, talvez, uma melhoria na padronização e programação das compras desses produtos por parte da Secretaria de Saúde do DF e uma atuação mais efetiva do Comitê Distrital da Saúde, pois essas garantias podem ter sido resolvidas extrajudicialmente.

Percebe-se também que as demandas judiciais por medicamentos no Distrito Federal predominaram aqueles não constantes nas relações oficiais. Portanto, fica evidente uma atuação do Judiciário local não condizente com as políticas públicas do SUS.

Nesse sentido, os resultados encontrados para a judicialização dos medicamentos no DF, nas variáveis analisadas, mostraram que é necessário alertar os profissionais de saúde prescritores para o grande número de medicamentos não padronizados que são garantidos judicialmente, adotando-se, se possível, medicamentos e formas de tratamentos mais específicas constantes das listas oficiais ou, então, incluindo esses medicamentos nas listas oficiais, como a REME-DF. Mostram ainda que há a necessidade de sensibilização do Poder Público para a padronização daqueles medicamentos mais judicializados e que contribuam para a coletividade, já que as decisões judiciais que garantem medicamentos no DF vêm de encontro às diretrizes do SUS.

\section{Referências}

1 Organização Mundial de Saúde-OMS. Constitution of the World Health Organization by 22 July 1946. Disponível na internet na URL:

http://apps.who.int/gb/bd/PDF/bd47/EN/constitution-en.pdf. [Acesso em 29.nov.2016].

2. Organização das Nações Unidas. The Universal Declaration of Human Rights by 10 December 1948. Disponível na internet na URL: http://www.un.org/en/documents/udhr/index.shtml\#atop. [ Acesso em 29.nov.2012].

3. Brasil Lei federal $n^{\circ} 8080$ de 19 de setembro de 1990. Disponível na internet na URL: http://portal.saude.gov.br/portal/arquivos/pdf/lei8080.pdf. [ Acesso em 8.set.2012].

4. Brasil. Conselho Nacional de Saúde. Resolução n 338 de 6 de maio de 2004. Aprova a Política Nacional de Assistência Farmacêutica. Diário Oficial da União, Poder Executivo, Seção 1, n. 96, 20 de maio de 2004. Brasília: Ministério da Saúde, 2004 
5 Delduque, M C.; Marques, Silvia B. A judicialização da política de assistência farmacêutica no Distrito Federal: diálogos entre a política e o direito. Revista Tempus Actas de Saúde Coletiva, Brasília, v. 5, n. 4, 2011, p. 98.

6. Vianna, L W et al. A judicialização da política e das relações sociais no Brasil. Rio de Janeiro: REVAN, 1999.

7.Penalva, J et al. Judicialização do direito à saúde: o caso do Distrito Federal. Belo Horizonte: Faculdade de Filosofia e Ciências Humanas, 8.2011.

8. Pepe, V L.E et al. A judicialização da saúde e os novos desafios da gestão da assistência farmacêutica. Ciência \& Saúde Coletiva, Rio de Janeiro, 15: 2405-2414, 2010a.

9.Conselho Nacional de Justiça. Disponível na internet na URL:

http://www.cnj.jus.br/noticias/judiciario/20194-comite-de-saude-discute temas-relevantessobre-saude-publica-no-df [ Acesso em 20.set.2012].

10. Brasil. Constituição da República Federativa do Brasil de 8 de outubro de 1988. Brasília: Senado Federal, 2011.

11.Brasil. Ministério da Saúde. Portaria GM/MS n 507 de 27 de abril de 1999. Publica a revisão da Relação Nacional de Medicamentos Essenciais, que acompanha esta portaria. Diário Oficial da República Federativa do Brasil, Brasília, 27 abril 1999. Poder Executivo. Seção I.

12. Brasil. Lei federal $n^{\circ} 12401$ de 28 de abril de 2011. Disponível na internet na URL: http://www.planalto.gov.br/ccivil_03/_Ato2011-2014/Lei/L12401.htm. [ Acesso em 8.out.2012).

13. Brasil. Decreto $n^{\circ} 7508$ de 28 de junho de 2011. Disponível na internet na URL: http://www.planalto.gov.br/ccivil_03/_Ato2011-2014/2011/decreto/D7508.htm. [ Acesso em 8.out.2012).

14. Brasil. Lei complementar $n^{\circ} 141$ de 13 de janeiro de 2012. Disponível na internet na URL: http://www.planalto.gov.br/ccivil_03/leis/LCP/Lcp141.htm. [Acesso em 8. out.2012].

15.Brasil. Ministério da Saúde. Portaria n 3916 de 10 de novembro de 1998. Aprova a Política Nacional de Medicamentos. Diário Oficial da República Federativa do Brasil, Brasília, 10 nov 1998. Poder Executivo. Seção I.

16. Marques, SB. A relação do sistema jurídico e do sistema político na garantia do direito social à assistência farmacêutica: o caso do Estado de São Paulo São Paulo. São Paulo: Dissertação de Mestrado - USP, Faculdade de Saúde Pública, 2005.

17. Brasil Ministério da Saúde. Protocolos Clínicos e Diretrizes Terapêuticas. Série A. Normas e Manuais Técnicos. Brasília - DF, 2010.

18. Distrito Federal. Lei Orgânica do Distrito Federal de 8 de junho de 1993. Disponível na internet na URL: http://aespdf.org/DF_Lei_Organica.pdf. [ Acesso em 8.set.2012].

19. Barbosa, S. Financiamento da saúde: ferramenta de concretização do direito à saúde. In: O direito achado na rua: introdução crítica ao direito à saúde, Costa, Alexandre Bernardino et al. (Org.), Brasília: CEAD/UnB, 2008, p. 281-289. 
Cuadernos Iberomericanos

de Derecho Sanitario

20. Santana, R N. A saúde aos cuidados do Judiciário: a judicialização das políticas públicas de assistência farmacêutica no Distrito Federal a partir da jurisprudência do TJDFT. Brasília: Dissertação de Mestrado - UnB, Faculdade de Direito, 2009.

21. Romero, LC. Judicialização das políticas de assistência farmacêutica: o caso do Distrito Federal. Consultoria Legislativa do Senado Federal. Brasília, 2008. 